\title{
Adapting MARSSIM for FUSRAP Site Closure
}

\section{R. Johnson*, L. Durham*, C. Rieman ${ }^{\dagger}$, and R. Hoover ${ }^{\dagger}$ \\ "Environmental Assessment Division Argonne National Laboratory, 9700 S. Cass Ave., Argonne, IL 60439 \\ U.S. Army Corps of Engineers, Buffalo District, 1766 Niagara Street, NY 14207}

The Multi-Agency Radiation Survey and Site Investigation Manual (MARSSIM) provides a coherent, technically defensible process for establishing that exposed surfaces satisfy site cleanup requirements. Unfortunately, many sites have complications that challenge a direct application of MARSSIM. Example complications include Record of Decision (ROD) requirements that are not MARSSIM-friendly, the potential for subsurface contamination, and incomplete characterization information. These types of complications are typically the rule, rather than the exception, for sites undergoing radiologically-driven remediation and closure. One such site is the Formerly Utilized Sites Remedial Action Program (FUSRAP) Linde site in Tonawanda, New York. Cleanup of the site is currently underway. The Linde site presented a number of challenges to designing and implementing a closure strategy consistent with MARSSIM. This paper discusses some of the closure issues confronted by the U.S. Army Corps of Engineers Buffalo District at the Linde site, and describes how MARSSIM protocols were adapted to address these issues. 


\section{INTRODUCTION}

The Multi-Agency Radiation Survey and Site Investigation Manual (MARSSIM) (EPA 2000) provides a coherent, graded, technically defensible, performance-based process for establishing that cleanup requirements have been met for surfaces at radiologically contaminated sites undergoing remediation and closure. Since its publication, MARSSIM has gained increasingly broad support as the closure process of choice. A good example of this support can be found within the Formerly Utilized Sites Remedial Action Program (FUSRAP), where most if not all sites attempt to base their site closure process on MARSSIM.

The U.S. Army Corps of Engineers (USACE) Buffalo District is responsible for remediating several radiologically contaminated sites related to the Manhattan Project under FUSRAP. These sites currently include the Ashland 1, Ashland 2, Linde, Seaway, and Niagara Storage sites in New York, and the Painesville and Luckey sites in Ohio. For those sites where

remediation activities are either complete (such as the Ashland 2 site) or underway (such as the Linde site), the closure process has been modeled after MARSSIM.

Unfortunately, applying MARSSIM to sites is often complicated by the constraints of MARSSIM's scope and assumptions. This fact has been particularly true at FUSRAP facilities, with legacy issues associated with sparse characterization data, potential subsurface contamination, and Records of Decisions (RODs) that have been derived primarily from Applicable or Relevant and Appropriate Requirements (ARARs).

\section{MARSSIM COMPLICATIONS}

MARSSIM imposes several constraints on its application, and, in general, three have had the greatest impact on successful MARSSIM implementation. 
The first and foremost of these constraints is the presumption that a dose- or risk-based goal exists, that this goal represents the cleanup requirement for the site, and that this goal can be translated into derived concentration guideline levels (DCGLs). A risk- or dose-based goal may not always be available for a site. For example, for ${ }^{226} \mathrm{Ra}$, cleanup requirements are often promulgated rather than derived (e.g., Uranium Mill Tailings Radiation Control Act [UMTRCA]). For some sites, references to ARARs may form the basis for part or all of the cleanup requirements. Sites may have inherited pre-MARSSIM RODs or negotiated cleanup standards for specific radionuclides that are only partially based on a site-specific risk or dose analysis. Finally, even if a dose- or risk-based goal exists, there may be additional requirements that do not fit this mold, such as radon emanation constraints.

The second MARSSIM constraint is that its closure methods are only intended for the surfaces of buildings and surficial soils. Subsurface soils, soil piles, buried infrastructure, and groundwater all fall outside the defined scope of MARSSIM. For many sites, however, the volume of these types of potentially contaminated media may dwarf potentially impacted surface areas. The site closure process needs to address these in situ concerns as well.

The third MARSSIM constraint is that often sufficient information is not available prior to the onset of the closure process to implement MARSSIM's graded approach to final status survey design. MARSSIM's graded approach manifests itself primarily through the division of a site into various classes of survey units. Survey unit class designation depends on the presumed potential for contamination being present above DCGL requirements. These survey unit designations range from Class 1 units covering areas where remediation is taking place to Class 3 units where there is no existing evidence and a low probability of contamination above DCGL requirements. MARSSIM invests the bulk of its final status survey effort into Class 1 
units, with relatively lesser amounts of information collected from Class 2 and Class 3 units. The benefit is that data collection efforts are targeted to the greatest need. The presumption, however, is that the data exist to support proper survey unit designations.

If the MARSSIM framework is followed from start to finish, this third constraint should not be an issue. For many sites, however, much of the initial characterization work was performed before the initial publication of MARSSIM in 1997. In many cases, these characterization data are sparse and inadequate for MARSSIM demands. For a variety of reasons, including schedule demands and stakeholder expectations, there is often pressure to push ahead with remediation and closure although adequate characterization information may not be available. It is expected that this third constraint will diminish over time as future site investigations are conducted using MARSSIM guidance.

\section{LINDE SITE}

The FUSRAP Linde site, outside Tonawanda, New York, is an example of a site affected by MARSSIM's constraints, and it exemplifies how the MARSSIM closure process can be modified to provide a technically defensible, performance-based process for site closure. The Linde site is currently undergoing remediation; excavated contaminated material is being shipped off-site for recycling or disposal. The USACE Buffalo District intends to close the site by using MARSSIM to the extent possible.

The Linde site comprises about 55 ha (135 acres) and consists of various office buildings, fabrication facilities, warehouse storage areas, material laydown areas, and parking lots. The Linde site is currently owned by Praxair, Inc. As a result of Manhattan Engineer District (MED) ore-handling activities on site, currently soils and some of the buildings are contaminated with radionuclides. The principal radionuclides of concern include ${ }^{226} \mathrm{Ra},{ }^{230} \mathrm{Th}$, and total uranium. 
Closure of subsurface soils is an issue for the Linde site. While much of the MED residues were probably deposited on or near the surface, subsequent earthmoving activities associated with building construction and landscaping have resulted in subsurface contamination overlain by clean backfill throughout the site. Traditional mobile gamma scans are relatively ineffective in identifying areas of potential concern because of the known covering of the MED residues due to building construction and landscaping activities.

The division of the Linde site into final status survey unit classes had to be based on incomplete data sets. The remedial investigation/feasibility study (RI/FS) for Linde yielded 1,074 samples from 385 soil bores. The bulk of this characterization activity, however, was concentrated in relatively few locations across the site that were in areas of highest subsurface contamination potential. This meant large portions of the facility had not been characterized. When the USACE assumed responsibility for this site after the RI/FS phase, there was considerable pressure from stakeholders to move forward with remediation and closure activities. The original in situ contaminated soil volume estimate for the site on the basis of RI/FS data and the ROD criteria was $36,000 \mathrm{~m}^{3}\left(47,000 \mathrm{yd}^{3}\right)$. However, preexcavation exploration activities conducted by the USACE and its contractors identified contaminated areas previously unknown. In addition, as excavation work began, excavation footprints grew in pursuit of buried contamination whose lateral extent had been hidden by clean backfill. The current in situ estimate of contaminated soil volume has grown to $47,000 \mathrm{~m}^{3}\left(62,000 \mathrm{yd}^{3}\right)$.

The Linde ROD requirements did not mesh with MARSSIM's assumptions of how DCGLs would be obtained for site closure. The Linde ROD (USACE 2000a) was based on an ARAR analysis and a radiological dose assessment for the radionuclides of concern (i.e., total uranium, ${ }^{226} \mathrm{Ra}$, and $\left.{ }^{230} \mathrm{Th}\right)$. On the basis of this analysis, the ROD contained basically two 
requirements. The first requirement was removal of contaminated soils with residual radionuclide concentrations averaged over a $100-\mathrm{m}^{2}$ area exceeding unity for the sum of ratios (SOR). The SOR calculation was based on the ratio of these radionuclide concentrations to their associated concentration limits. These concentration limits, as measured above background, were $20.5 \mathrm{~Bq} / \mathrm{g}(554 \mathrm{pCi} / \mathrm{g})$ of total uranium, $0.19 \mathrm{~Bq} / \mathrm{g}(5 \mathrm{pCi} / \mathrm{g})$ of ${ }^{226} \mathrm{Ra}$, and $0.52 \mathrm{~Bq} / \mathrm{g}(14 \mathrm{pCi} / \mathrm{g})$ of ${ }^{230} \mathrm{Th}$ for surface cleanups, and $112 \mathrm{~Bq} / \mathrm{g}(3,021 \mathrm{pCi} / \mathrm{g})$ of total uranium, $0.56 \mathrm{~Bq} / \mathrm{g}(15 \mathrm{pCi} / \mathrm{g})$ of ${ }^{226} \mathrm{Ra}$, and $1.6 \mathrm{~Bq} / \mathrm{g}\left(44 \mathrm{pCi} / \mathrm{g}\right.$ ) of ${ }^{230} \mathrm{Th}$ for subsurface cleanups. The second requirement was that USACE remediate the Linde site to ensure that no concentration of total uranium exceeding $22 \mathrm{~Bq} / \mathrm{g}(600 \mathrm{pCi} / \mathrm{g})$ above background would remain in site soils. In addition, supporting documentation to the Linde ROD indicated that the remediation process at Linde would leave soils with residual concentrations, averaged over large areas, well below the required SOR and total uranium criteria (USACE 2000b). The expected residual radionuclide concentrations, incremental to background, were $0.074 \mathrm{~Bq} / \mathrm{g}(2 \mathrm{pCi} / \mathrm{g})$ for ${ }^{226} \mathrm{Ra}, 0.13 \mathrm{~Bq} / \mathrm{g}(3.5 \mathrm{pCi} / \mathrm{g})$ for ${ }^{230} \mathrm{Th}$, and $2.25 \mathrm{~Bq} / \mathrm{g}(60.8 \mathrm{pCi} / \mathrm{g})$ for total uranium.

\section{ADAPTING MARSSIM for LINDE COMPLICATIONS}

The first challenge in designing a MARSSIM-consistent final status survey strategy was accommodating the Linde ROD requirements. MARSSIM's DCGLs are posed as wide area average values $\left(\mathrm{DCGL}_{\mathrm{w}}\right)$ or as elevated area measurement comparisons $\left(\mathrm{DCGL}_{\mathrm{emc}}\right)$ over much smaller areas. DCGL $\mathrm{w}_{\mathrm{w}}$ values typically apply to areas the size of final status survey units, which for MARSSIM range up to 2,000 $\mathrm{m}^{2}$ for Class 1 units and 10,000 $\mathrm{m}^{2}$ for Class 2 units. DCGL $\mathrm{L}_{\mathrm{emc}}$ values apply to areas much smaller than the size of a final status survey unit. 
The second Linde ROD requirement, the never-to-exceed requirement for total uranium, clearly can function as a $\mathrm{DCGL}_{\mathrm{emc}}$. Fortunately, the total uranium requirement is large enough to lend itself to detection in surface soils with mobile gross gamma screening techniques. The first Linde ROD requirement, however, is more problematic. The size of the averaging area specified for the SOR requirement in the ROD was much smaller than a standard MARSSIM final status survey unit. If the SOR requirement is treated as a $\mathrm{DCGL}_{\mathrm{w}}$ requirement, implying a final status survey unit size of $100 \mathrm{~m}^{2}$, and the Sign or Wilcoxon Rank Sum (WRS) test is used to demonstrate compliance, the result would be a prohibitive number of discrete samples for the site as a whole. While MARSSIM presumes nonparametric statistical tests and discrete sampling programs for demonstrating $\mathrm{DCGL}_{\mathrm{w}}$ compliance, it is more lenient with methods for demonstrating DCGL $_{\mathrm{emc}}$ compliance. In particular, MARSSIM's method of choice is scanning technologies, assuming that technologies with appropriate sensitivities exist. If scanning technologies do not exist with adequate sensitivities, MARSSIM falls back to discrete samples. In the case of Linde's SOR requirement, the size of the averaging area resembles a $\mathrm{DCGL}_{\mathrm{emc}}$ more than a DCGL $\mathrm{w}$. In addition, the radionuclides of concern and their cleanup requirements (with the exception of ${ }^{230} \mathrm{Th}$ ) are amenable to detection by scanning technologies. In this context, ${ }^{230} \mathrm{Th}$ turns out not to be a closure issue since ${ }^{226} \mathrm{Ra}$ and total uranium predominate. For the Linde site, a decision was made to treat the SOR requirement as a $\mathrm{DCGL}_{\mathrm{emc}}$ as well. Compliance for surface soils was demonstrated by surface scans, substantiated by one discrete soil sample per $100 \mathrm{~m}^{2}$ in Class 1 units, with the discrete soil samples used primarily for quality assurance/quality control purposes. 
After the ROD was finalized, considerable discussion took place whether to treat the expected residual concentrations (identified in supporting ROD documentation) as a $\mathrm{DCGL}_{\mathrm{w}}$ for the site. The final decision was not to treat them as a $\mathrm{DCGL}_{\mathrm{w}}$ for basically two reasons. First, these expected residual concentration values were never intended to function as a formal requirement. Second, to demonstrate compliance with these low residual concentration values using nonparametric techniques and discrete samples would require remediating site soils to even lower values (known in MARSSIM parlance as the Lower Bound of the Grey Region, or LBGR).

The second complication confronting the implementation of MARSSIM at the Linde site was the presence of subsurface contamination, which raised issues for two reasons. First, it made the use of surface scanning techniques ineffective for determining the presence or absence of contamination. Second, it was not immediately clear how to interpret the ROD requirements in the context of subsurface soils or the type of data collection and decision processes required for demonstrating closure. In Class 1 areas (areas where remediation was taking place), the presumption was that residual subsurface contamination above cleanup requirements would not be an issue because excavation would continue until clean soils were encountered. The issue of potential subsurface contamination applied to Class 2 and Class 3 areas. On the basis of all the data collected to date, soil contamination is below the existing surficial landscape layer and above the original topography of the site (i.e., native soil).

The approach was to apply the subsurface SOR requirement to each 15.2-cm (6-in.) interval at depth. Establishing compliance for each $100-\mathrm{m}^{2}$ area and each 15.2-cm (6-in.) depth down to native soil in Class 2 areas again presented a potentially enormous number of physical samples. Fortunately, the cleanup requirements for subsurface soils in the ROD allowed the use 
of screening techniques to be applied to subsurface soil cores. A customized core scanner was developed, and a GeoProbe system was used to obtain cores. Gross gamma investigation levels developed for the core scanner provided a 95\% confidence level for detecting potential ROD exceedances in any given 15.2-cm (6-in.) interval. Intervals that failed the scan were sampled and analyzed using gamma and alpha spectroscopy. In addition, a limited number of vertically composited soil samples were collected across each Class 2 unit to allow a determination of the average residual contamination present.

The final complication was the fact that the Linde site was moving aggressively into remediation and closure on the basis of limited characterization data. The main implication of this for implementing MARSSIM was that the classification of the site into Class 1, Class 2, and Class 3 areas was based on less data than might be optimal initially. The solution in the case of Linde was to do the best possible classification and then to incorporate more final status survey data collection within the Class 2 areas than might otherwise have been required. For example, a surficial scan was completed for all accessible areas, rather than the more limited scanning MARSSIM references for Class 2 units. In addition, at least one GeoProbe core was obtained for every $100-\mathrm{m}^{2}$ area. Final status survey work began in the Class 2 and Class 3 areas before excavation work was complete in the Class 1 areas to take advantage of the presence of excavation crews. Thus, if unexpected contamination was encountered in Class 2 and/or Class 3 areas, it could be dealt with immediately.

\section{CONCLUSIONS}

MARSSIM has done much to standardize approaches to demonstrating closure at sites contaminated with radionuclides. Most sites, however, involve constraints that defy direct application of MARSSIM. Sites within FUSRAP are no exception. The most common 
constraints involve cleanup requirements that are not consistent with MARSSIM's dose- or riskbased derived activity concentration guideline concepts, subsurface contamination issues, and inadequate site characterization information. As the Linde site demonstrates, however, these types of constraints can be addressed with a little imagination and some modifications to MARSSIM's methods. The result provides a technically defensible, performance-based process for site closure.

\section{REFERENCES}

Environmental Protection Agency. Multi-agency radiation survey and site investigation manual (MARSSIM); NUREG-1575, Rev. 1; EPA 402-R-97-016, Rev. 1; DOE/EH-0624, Rev. 1; 2000.

U.S. Army Corps of Engineers. Record of Decision for the Linde site Tonawanda, New York, U. S. Army Corps of Engineers, Buffalo District, Formerly Utilized Sites Remedial Action Program; 2000a.

U.S. Army Corps of Engineers. Technical Memorandum: Linde site radiological assessment, Tonawanda, New York, U.S. Army Corps of Engineers, Buffalo District Office, Formerly Utilized Sites Remedial Action Program; 2000b. 